Gut, 1989, 30, 1750-1756

Liver, biliary, and pancreas

\title{
Biliary lipid composition in monozygotic and dizygotic pairs of twins
}

\author{
Y ANTERO KESÄNIEMI, M KOSKENVUO, M VUORISTO, \\ AND T A MIETTINEN \\ From the Second Department of Medicine and the Department of Public Health, University of Helsinki, \\ Helsinki, and the Department of Internal Medicine, University of Oulu, Oulu, Finland
}

SUMMARY The relative contribution of genetic factors to biliary and serum lipid composition was studied in 17 monozygotic and 18 dizygotic middle aged male pairs of twins. Cholesterol precursors, squalene and Methylated sterols which reflect the activity of cholesterol synthesis were also measured. Pairwise intraclass correlations were determined for monozygotic and dizygotic twin pairs and heritability estimates were calculated. Molar \% of biliary cholesterol and percentage distribution of biliary cholic acid and particularly deoxycholic acid showed significant pairwise correlations within the monozygotic but not the dizygotic pairs. Similar correlations were found for total biliary methylsterols and of the methylsterol subfractions for the two methostenols but not for squalene, lanosterol and dimethylsterols. In serum, the precursor sterols, but not squalene, showed even higher pairwise correlations in the monozygotic twins than the corresponding precursors in bile. Molar per cent of bile acids and phospholipids and cholesterol saturation index were not correlated significantly in either twin pairs, but the pairwise correlations tended to be higher in the monozygotic than in the dizygotic pairs. Gall stones were found in seven monozygotic and three dizygotic subjects. Two monozygotic twin pairs were concordant for gall stones; all the dizygotic pairs were discordant. Overall, these data suggest that molar percentage of biliary cholesterol, bile acid composition, cholesterol synthesis, bile cholesterol saturation, and gall stone formation may be under a significant genetic control.

Several environmental factors such as diet, treatment with steroid hormones and other medications, may contribute to the development of gall stones, particularly cholesterol cholelithiasis. ${ }^{1}$ An increased familial frequency of gall stones has also been suggested, however. ${ }^{2-7}$ Therefore, it is possible that gall stone formation is partly under genetic control. Cholesterol in bile is carried in vesicles as well as in micelles and a prerequisite for the development of cholesterol gall stones is lithogenic bile that contains more cholesterol than can be dissolved. ${ }^{1 \times 4}$ The relative contribution of genetic and environmental factors. to the biliary cholesterol saturation is not known. Monozygotic twins have the same genes while

Address for correspondence: Professor Y Antero Kesäniemi, MD. Department of Internal Medicine. University of Oulu, Kajaanintie 50. SF-9(220) Oulu. Finland.

Accepted for publication 21 March 1989. dizygotic pairs are like any other full siblings. Therefore, anything under strong genetic control should have a high pairwise correlation in the monozygotic twins, but a $0 \cdot 5$-fold association should be seen within the dizygotic pairs of twins. Thus, the twin method offers a useful tool for the evaluation of genetic and environmental components in the pathogenesis of cholesterol cholelithiasis. The present study was carried out to determine serum and biliary lipids and heritability estimates for these metabolic components.

\section{Methods}

SUBJECTS

Male twins (17 monozygotic and 18 dizygotic pairs) living apart in the Helsinki area were randomly selected from the Finnish Twin Cohort." The age of 
the subjects ranged from 43 to 58 years (mean 50 ). None of the subjects had any clinically manifest cardiovascular, endocrinological, renal or gastrointestinal disease. The body weight ranged from 56 $\mathrm{kg}$ to $103 \mathrm{~kg}$ with a mean of $78 \mathrm{~kg}(9 \cdot 5, \mathrm{SD})$. The body mass index (weight/height ${ }^{2}$ ) ranged from 19 to 32 with a mean of 25 . The zygosity diagnosis was established by mailed questionnaire as previously described. ${ }^{11-14}$ The determination of zygosity by this method has been validated by the analysis of 11 blood markers in another group of twins in the Helsinki area." 'I All the patients volunteered for the studies which was approved by the Ethical Committee of our hospital.

STUDY PROTOCOL

All the subjects were studied as outpatients with three visits to the outpatient clinic. The first visit was made for medical history, physical examination, and routine blood tests. One week later oral cholecystography was performed during the second visit. The third visit was two weeks after the initiation of the study when, during fasting, gall bladder bile, and serum samples were obtained simultaneously for lipid analysis. The duodenum was intubated under fluoroscopic control by a single lumen tube after a 12 hour fast and duodenal bile was aspirated using cholecystokinin to provoke gall bladder contraction.

DIETS

The patients were studied on their regular home diet. They were advised to keep a food record for nine days and the dietary consumption was determined by a modified food record method. ${ }^{15}$ The consumption of dietary constituents was calculated from the record as previously described. ${ }^{16}$ This method has been shown to measure dietary constituents such as dictary cholesterol intake reasonably accurately. ${ }^{17}$ In fact, we found that the values by direct quantitation and the dietary recall method were not significantly different from each other in a small group of various patients." The mean daily caloric consumption was $31 \cdot 1 \mathrm{kcal} / \mathrm{kg}$ (6.4 SD). On average, $14.2(1.5) \%$ of the calories were obtained from protein, $39 \cdot 5(5 \cdot 3) \%$ from fat, $43.2(5 \cdot 7) \%$ from carbohydrates, and $3 \cdot()(4 \cdot 6) \%$ from alcohol. Dietary cholesterol intake ranged from 200 to $867 \mathrm{mg} /$ day with a mean of $439 \mathrm{mg} /$ day $(132$ SD), and the ratio of polyunsaturated to saturated fat $(\mathrm{P} / \mathrm{S}$ ratio) averaged ()$\cdot 24(0 \cdot 11)$.

SERUM AND BII.IARY LIPIDS

Serum total cholesterol and triglycerides were determined according to the routine methods of our hospital laboratory. ${ }^{19}$ 느 Total biliary bile acids and bile acid distribution was determined by gas liquid chromatography. ${ }^{21}$ Biliary phospholipids were measured by Bartlett's method"= using the Fiske-

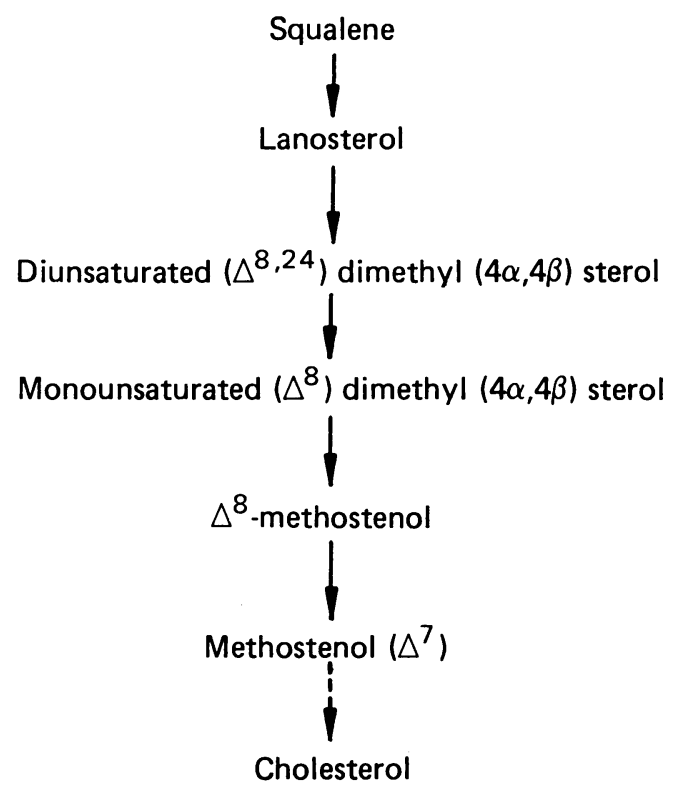

Fig. 1 Schematic illustration of squalene conversion to cholesterol as determined in the present study.

Subbarow reagent." Serum and biliary squalene, serum free methylsterols and free cholesterol (Fig. 1) were isolated and measured by thin layer chromatography gas chromatography as previously described. ${ }^{-1}$ The respective biliary sterol analyses were performed from non-saponifiable material. Five major methylated precursor sterols were identified in increasing order of retentions: (1) $\Delta^{s}$-methostenol

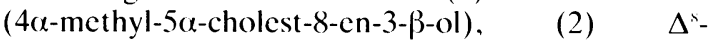
demethylsterol $(4 \alpha, 4 \beta$-dimethyl-5 $3 \beta$-cholest- 8 -en$3(\beta-\mathrm{ol})$, (3) methostenol ( $4 \alpha$-methyl-5 $\alpha$-cholest-7-

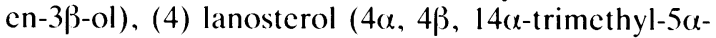
cholest-8, 24 dien-3(j-ol), and (5) $\Delta^{\mathrm{x}-24}$-dimethylsterol ( $4 \alpha, 4 \beta$-dimethyl-5 $\alpha$-cholest- 8,24 -dien-3 3 -ol). To minimise the effect of different lipid concentrations, the cholesterol precursors are mainly expressed in terms of $\mu \mathrm{g} / \mathrm{mg}$ of the serum free or total biliary cholesterol.

\section{BIIIARY CHOLESTEROL SATURATION}

Lipid composition of bile was calculated as the molar percentages of cholesterol, bile acids, and phospholipids. In addition, the cholesterol saturation index of bile samples was determined using the solubility limits for cholesterol proposed by Admirand and Small. ${ }^{\circ}$

STATISTICAL. ANALYSIS

The monozygotic and dizygotic twin pairs were compared calculating pairwise intraclass correla- 


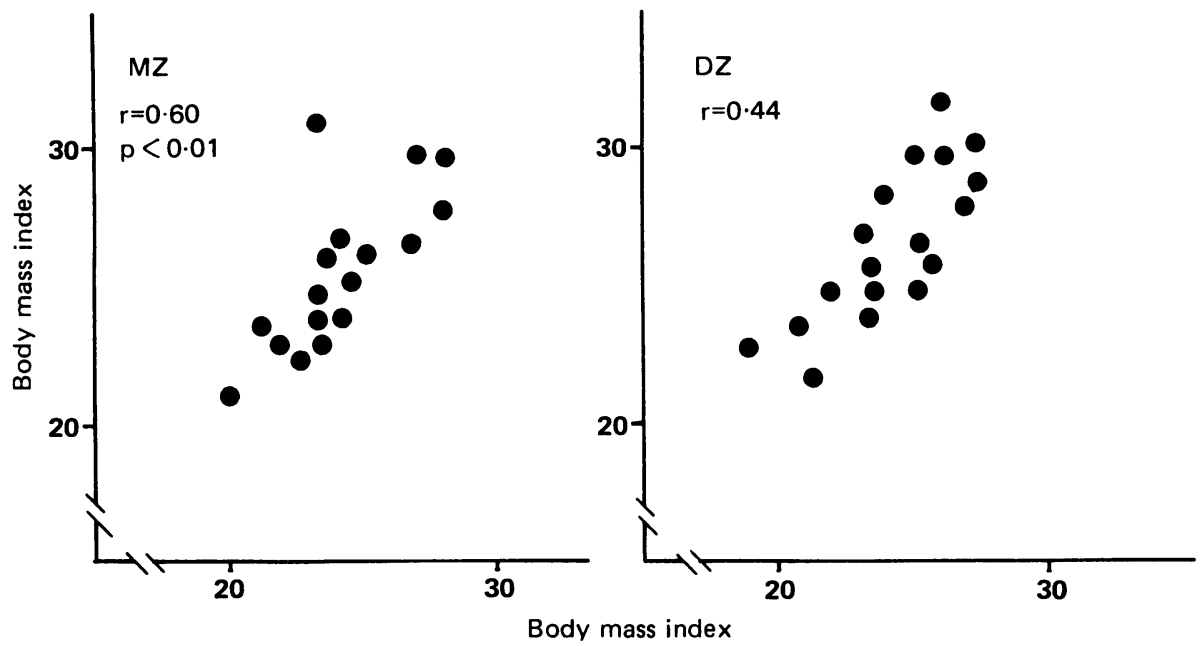

Fig. 2 Pairwise intraclass correlation of body mass index in monozygotic (MZ) and di-ygotic (DZ) wins.

tions $(r)$. Heritability estimates $\left(h^{2}\right)$ were calculated according to Jensen..$^{25}$ The upper limit of heritability was estimated from the following formulas: (1) $h^{2}=$ $r_{M Z}$ - that is, heritability in monozygotic cotwins reared apart, (2) $h^{2}=2\left(r_{M Z}-r_{D z}\right)-$ that is, heritability from monozygotic and dizygotic cotwins reared together. Heritability estimates are given by formula 2 except in cases when heritability estimates exceeds $r_{M z}$. Also, the role of some environmental factors (mainly dietary) in the regulation of bile and serum lipid metabolism was estimated by calculating the correlations between the intrapair differences of the dietary components and the intrapair differences of the lipid metabolism in monozygotic twins. The intrapair difference indicates a difference of a variable between the members of a twin pair. This was mainly done for testing the possibility that some environmental factors may be more similar among the monozygotic than dizygotic cotwins and may therefore confound the pairwise analyses for the estimation of heritability. The correlation cocfficients were calculated taking into account the observed log-normal distribution of the study parameters.

\section{Results}

The pairwise correlation for the body mass index was somewhat higher for monozygotic $(\mathrm{r}=0 \cdot 60, \mathrm{p}<0 \cdot() 1)$ than dizygotic $(r=0.44)$ twins, indicating that the monozygotic pairs were more alike with regard to their body habitus than the dizygotic twins (Fig. 2). Table 1 shows the biliary and serum lipids and biliary cholesterol saturation among all the subjects. The biliary contents of cholesterol precursor sterols, especially that of lanosterol, were several times higher than the corresponding free sterols in serum.

BILIARY LIPIDS

The pairwise correlation coefficients for biliary lipids and bile cholesterol saturation percentages in the monozygotic and dizygotic twin pairs are shown in Table 2. Molar percentage of cholesterol, but not bile acids and phospholipids, was significantly correlated in the monozygotic pairs. These correlations were insignificant in the dizygotic twins. The percentages of cholic acid and especially deoxycholic acid (Fig. 3), but not of chenodeoxycholic acid, showed a signifi-

Table 1 Biliary and serum lipids and biliary cholesterol saturation among all the subjects

\begin{tabular}{|c|c|c|}
\hline & Bile** & Sorumt \\
\hline Triglycerides & - & $1 \cdot 5(0 \cdot 1) \div \div$ \\
\hline Squalenes & $75(7) \div$ & $40(.3)$ \\
\hline Sum of the methylsterols & $1234(70)$ & $84(5)$ \\
\hline Lanosterolș & $681(40)$ & $29(1)$ \\
\hline$\Delta{ }^{\prime}$-dimethylsterols & $189(12)$ & $19(1)$ \\
\hline$\Delta$-dimethylsterolș & $6+(3)$ & $8(1)$ \\
\hline$\Delta$-methostenolș & $194(13)$ & $16(1)$ \\
\hline Methostenolș & $106(7)$ & $13(1)$ \\
\hline Cholesterol\| & $9 \cdot()(0 \cdot 3)$ & $6 \cdot()(0 \cdot 1) \div \div$ \\
\hline Phospholipids: & $18.5(0.5)$ & - \\
\hline Bile acids & $72.5(1) \cdot 6)$ & - \\
\hline Cholic acid $\%$ & $47 \cdot 1(0.9)$ & - \\
\hline Deoxycholic acid $\%$ & $14 \cdot 2(1 \cdot 1)$ & - \\
\hline (henodeoxycholic acid $\% 9$ & $38 \cdot 7(() \cdot 7)$ & - \\
\hline Cholesterol saturation $\% * *$ & $96(4)$ & - \\
\hline
\end{tabular}

"Determined in $6(0)$ subjects: + Determined in all 70 subjects: $t$ The results are given as mean (SE): $\$$ Expressed as $\mu \mathrm{g} / \mathrm{mg}$ of cholesterol: in serum for free, in bile for total sterols: |Molar percentage: TPercent of total bile acids: * Calculated according to Admirand and Small: $+t \mathrm{mmol} / \mathrm{l}$. 


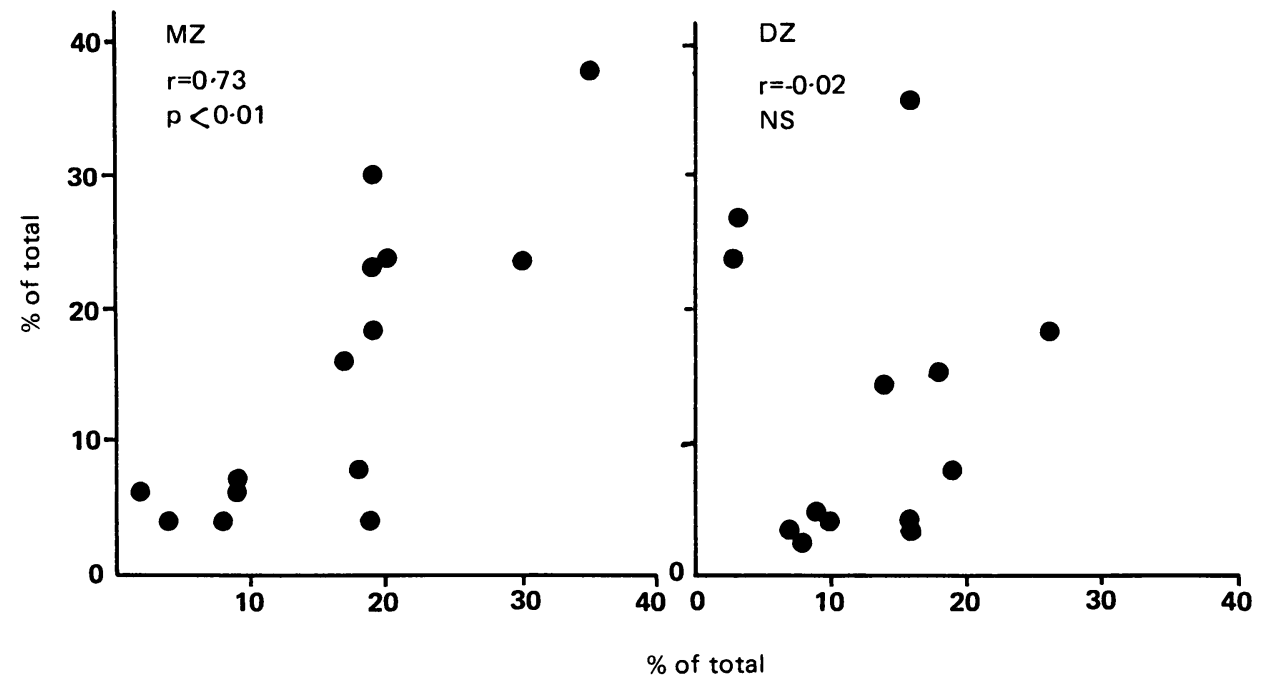

Fig. 3 Pairwise intraclass correlation of biliary deoxycholic acid (per cent of total bile acids) in monosygotic (MZ) and dizygotic (DZ) wins.

cant pairwise correlation in the monozygotic twins, whereas no correlation was found in the dizygotic pairs. Heritability estimates were high for the molar percentage of biliary cholesterol $(0 \cdot 47)$ and the percentages of biliary bile acids (from 0.28 to 0.73 ). Of the biliary cholesterol precursor sterols the two methostenols and the sum of methylsterols were significantly correlated in the monozygotic twin

Table 2 Pairwise intraclass correlation coefficients for biliary lipids and cholesterol saturation in monozygotic and dizygotic pairs of twins

\begin{tabular}{|c|c|c|c|}
\hline \multirow[b]{2}{*}{ Biliary lipid } & \multicolumn{2}{|c|}{ Correlation coefficient } & \multirow[b]{2}{*}{$\begin{array}{l}\text { Heritability } \\
\text { estimate }\end{array}$} \\
\hline & $\begin{array}{l}\text { Mono-ygotic } \\
\text { twins }\end{array}$ & $\begin{array}{l}\text { Di-ygotic } \\
\text { twins }\end{array}$ & \\
\hline & $(r)$ & $(\mathrm{r})$ & \\
\hline Cholesterol M \%* & $0.47 \$$ & $-0 \cdot(19)$ & 0.47 \\
\hline Bile acids $\mathrm{M} \% *$ & 0.08 & $-0 .(17$ & 0.08 \\
\hline Phospholipids M \%* & $-0 \cdot 13$ & $-(0 \cdot(0)$ & 0.00 \\
\hline Cholic acid \% & $0.58 \S$ & -0.25 & 0.58 \\
\hline Deoxycholic acid \% $\dagger$ & $0.73 \S$ & $-0 \cdot(02$ & 0.73 \\
\hline Chenodeoxycholic acid $\% \dagger$ & 0.28 & -0.34 & 0.28 \\
\hline Squalene & 0.36 & 0.33 & 0.06 \\
\hline Lanosterol & 0.43 & 0.46 & 0.00 \\
\hline$\Delta{ }^{\prime \prime}$-dimethylsterol & 0.41 & $0 \cdot 30$ & 0.22 \\
\hline$\Delta^{*}$-dimethylsterol & 0.38 & 0.03 & 0.38 \\
\hline$\Delta "$-methostenol & $0.54 \S$ & 0.05 & 0.54 \\
\hline Methostenol & $0.54 \S$ & $-0 \cdot 15$ & 0.54 \\
\hline Sum of the methylsterols & $0.48 \S$ & 0.32 & 0.32 \\
\hline Cholesterol saturation & 0.46 & $-0 \cdot(01$ & 0.46 \\
\hline
\end{tabular}

${ }^{*} \mathrm{M} \%=$ molar percentage $: \nmid$ Percentage of individual bile acid from total bile acids: $₫$ Calculated according to Admirand and Small : $\$ p<0 \cdot 0.5$ or less. pairs. The calculated heritability estimates for biliary methylsterols ranged from 0.22 to $(0.54$. The bile cholesterol saturation index showed insignificant pairwise correlations in the monozygotic and dizygotic twins, the heritability estimate being $0 \cdot 46$.

\section{GALI, STONES}

Two of the subjects had had cholecystectomy because of gall stones in their past history. In addition, previously unknown gall stones were observed in eight patients during the present studies. All the other subjects had normally visualised cholecystograms. Gall stones, including cholecystectomies for gall stones, were found in seven monozygotic and three dizygotic subjects. Two monozygotic twin pairs were concordant for gall stones - that is, both members of the pair had gall stones whereas all the dizygotic pairs were discordant. Therefore, the pairwise concordance for gall stones was $40 \%$ for monozygotic and $0 \%$ for dizygotic twins.

\section{SIERUM LIPIDS}

Table 3 shows the pairwise correlation coefficients for serum total cholesterol and triglyceride and for the serum cholesterol precursors, methylsterols, and squalene. Serum cholesterol and triglyceride levels were significantly correlated within the monozygotic pairs; for the dizygotic twins the pairwise correlation was significant only for plasma cholesterol. The calculated heritability estimates were $0 \cdot 26$ for serum cholesterol and $(0.60$ for serum triglyceride. All the serum methylsterols except methostenol were significantly correlated within the monozygotic but 
not in the dizygotic twins. The calculated heritability estimates for serum methylsterois ranged from 0.43 to 0.60 . Serum squalene was not significantly correlated in either pair of twins.

DIETARY INTAKE:

The pairwise correlation coefficients for various dietary components were insignificant in both the monozygotic and dizygotic twins: dictary cholesterol $\mathrm{r}_{\mathrm{MZ}}=-0 \cdot 13, \mathrm{r}_{\mathrm{DZ}}=() \cdot 42 ; \mathrm{P} / \mathrm{S}$ ratio $\mathrm{R}_{\mathrm{M} Z}=\left(0 \cdot 31, \mathrm{r}_{\mathrm{DZ}}=\right.$ 0.06 ; percentage of calories derived from fat $\mathrm{r}_{\mathrm{M} Z}=$ $0.34 ; r_{D Z}=-0.35$; from carbohydrates $r_{M Z}=0.25$; $\mathrm{r}_{\mathrm{DZ}}=0.28 ;$ from protein $\mathrm{r}_{\mathrm{MZ}}=-0 .\left(04 ; \mathrm{r}_{\mathrm{DZ}}=-0 \cdot 28\right.$; and from alcohol $\mathrm{r}_{\mathrm{MZ}}=() \cdot 16 ; \mathrm{r}_{\mathrm{DZ}}=() \cdot 42$.

CORREIATIONS BETWEEN THEINTRAPAIR

DIFFERENCES IN MONOZYGOTIC TWINS

Because the monozygotic twins share the same genes and still show some intrapair differences in biliary and serum lipids these differences must be the result of environmental factors. To clucidate the relative importance of these factors, the intrapair differences of the monozygotic twins in biliary and serum lipid components were correlated with those in environmental parameters studied. The intrapair difference between the monozygotic twins in the body mass index, calories derived from fat, carbohydrates, protein, and alcohol, dictary cholesterol, and P/S ratio showed only the following significant correlations with the intrapair differences between serum and bile lipids: dietary cholesterol intake $v$ molar percentage of biliary phospholipids $(r=0.45)$ $(p<0.05)$ and percentage of biliary chenodeoxycholic acid $(r=0.47)(p<0.05)$; calories derived from fat $v$ serum total cholesterol $(r=0 \cdot 51 ; p<0 \cdot() 5)$.

\section{Discussion}

The critical basis for twin studies is the correct diagnosis of zygosity. The zygosity of the twins in the Finnish Twin Cohort had previously been diagnosed by mailed questionnaire ${ }^{1314}$ and had also been validated by 11 blood group markers." "2 Therefore, the subjects studied in the present work were most probably correctly classificd into monozygotic and dizygotic pairs of twins.

In accordance with previous reports, ${ }^{20}$ we found serum total cholesterol and triglyceride concentrations to correlate closely within the monozygotic twins. The relative genetic contribution to the regulation of serum cholesterol concentration, however, remained fairly weak $(25 \%)$. In fact, the effect of environmental factors on serum cholesterol concentration is well known and dietary fat intake accordingly showed a positive correlation with serum total cholesterol when the intrapair differences in these
Table 3 Pairwise intraclass correlation coefficients for serum lipids in monozygotic and dizygotic pairs of twins

\begin{tabular}{|c|c|c|c|}
\hline \multirow[b]{2}{*}{ Serum lipid } & \multicolumn{2}{|c|}{ Correlation coefficient } & \multirow[b]{2}{*}{$\begin{array}{l}\text { Heritability } \\
\text { estimate }\end{array}$} \\
\hline & $\begin{array}{l}\text { Monozygotic } \\
\text { wins }\end{array}$ & $\begin{array}{l}\text { Di-ygotic } \\
\text { twins }\end{array}$ & \\
\hline & $(r)$ & $(r)$ & \\
\hline Total cholesterol & $0.67 *$ & $0.54 \%$ & 0.26 \\
\hline Total triglyceride & $0 \cdot 60 *$ & 0.11 & $0.60)$ \\
\hline Squalene & $0 \cdot 1.5$ & 0.41 & $0 .(10)$ \\
\hline Lanosterol & $0.63^{*}$ & 0.14 & 0.63 \\
\hline$\Delta^{-24}$-dimethylsterol & $(0.57 *$ & 0.19 & 0.57 \\
\hline$\Delta^{x}$-dimethylsterol & $0.50 \%$ & $0 \cdot 10$ & 0.50 \\
\hline$\Delta$-methostenol & $\left(0.47^{*}\right.$ & 0.14 & 0.47 \\
\hline Methostenol & $(0 \cdot 4.3$ & $0 .(1) 9$ & 0.43 \\
\hline Sum of the methylsterols & $(0.6)^{*}$ & $0 \cdot 16$ & $0 \cdot 60)$ \\
\hline
\end{tabular}

$* p<0.05$ or less.

parameters were plotted among the monozygotic twins. A strong pairwise correlation of serum triglyceride concentration within the monozygotic $(r=$ $0.60)$ but not in the dizygotic pairs $(\mathrm{r}=0.11)$ suggests a somewhat higher genetic control for serum triglyceride regulation in our series than has been noticed previously. ${ }^{26}$ Body mass index, however, showed a somewhat higher pairwise correlation in the monozygotic than dizygotic twins, and the degree of obesity is a well known factor regulating serum triglyceride concentrations.

The serum contents of methylsterols indicate the activity of hepatic cholesterol synthesis in many clinical conditions. ${ }^{27-2 "}$ In fact, in man the correlation of serum unesterified methylsterol concentrations with the hepatic hydroxymethyl glutaryl CoA reductase is highly significantly positive." Thus, the significant pairwise correlations of almost all individual methylsterols in the monozygotic, but not in the dizygotic pairs suggest that the activity of cholesterol synthesis, most probably in the liver, is under strong genetic regulation. Serum squalene was not correlated in either twin pairs probably because it appears to occur only transiently in parallel with acute changes in cholesterol synthesis. ${ }^{27-31}$ The cholesterol precursor contents of the monozygotic twins showed less frequent pairwise correlations in the bile than in serum and the significant association was found for the most polar methylsterols, methostenols only. This raises a question of genetic contribution to their biliary secretion. In fact, it is of interest to note that methostenols are markedly enriched in cholesterol gall stones while the less polar precursor sterols, especially lanosterol, remain mainly soluble in the bile."

The significant pairwise correlations of the molar percentage of cholesterol in the fasting duodenal bile 
in the monozygotic, but not the dizygotic twins suggests that biliary cholesterol metabolism is to some extent genetically controlled, probably through cholesterol synthesis as indicated by the precursor sterols. The high pairwise correlation of the relative cholic and deoxycholic acid contents in the monozygotic, but not in the dizygotic twins indicates genetic control in the metabolism of these two bile acids. In fact, because deoxycholic acid is a bacterial conversion product, formed mainly in the colon, the finding suggests that colonic bacterial flora or colonic absorption of deoxycholate is genetically controlled. The intestinal bacterial flora, however, is also strongly influenced by the diet. Even though the dietary review did not show any higher pairwise correlation among the monozygotic than the dizygotic pairs, the influence of some dietary factor(s), such as the type of fibre, is not totally excluded. As the dietary intakes were estimated by the dietary recording method instead of direct weighing of the food products, it is possible that the diet analysis missed some important findings.

Cholesterol gall stone formation is frequently associated with supersaturation of biliary cholesterol $^{1,8:-36}$ and cholesterol stones are the most frequent gall stones in Western societies ${ }^{37}$ including two populations of this country. ${ }^{3 \times}$ The present study shows that the intrapair correlation coefficient for the molar percentage and the saturation index of cholesterol are higher in the monozygotic than in the dizygotic pairs. This suggests that the development of supersaturated bile is also genetically controlled, possibly through genetically controlled cholesterol metabolism or biliary secretion. This was also suggested by a previous study ${ }^{34}$ where a higher cholesterol saturation of bile was found in younger sisters of patients with cholesterol gall stones than in those of non gall stone controls. Genetic regulation of bile cholesterol saturation, however, does not necessarily indicate genetic control of gall stone formation. As several investigators have pointed out $^{410-13}$ there are a number of subjects with supersaturated bile who do not develop cholelithiasis, and others who develop cholelithiasis without supersaturation, as shown by the National Gallstone Study." Genetic control of the critical physiochemical abnormality in the initiation of gall stone, cholesterol crystal formation, ${ }^{+14-2}$ is not known but this possibility is not ruled out. At any rate, genetic contribution to the gall stone formation was suggested by the findings of the present study that the monozygotic pairs showed a $40 \%$ concordance for gall stones compared with a complete discordance in the dizygotic twins.

The similar pairwise correlations of dietary components in the monozygotic and dizygotic twins indicate that the monozygotic pairs of the present study, intentionally selected from pairs living apart, did not have more similar dietary habits than the dizygotic twin pairs. This finding further supports the importance of genetic contribution in the regulation of cholesterol metabolism. Furthermore, of the many environmental factors regulating cholesterol and bile acid metabolism those determined in this study, diet, and the degree of obesity, are probably the most important. The intrapair differences between these environmental factors among the monozygotic pairs, however, showed surprisingly weak correlations with the intrapair differences between the measured parameters of cholesterol and bilc acid metabolism. This may still be additional evidence pointing towards significant genetic control in the regulation of these metabolic pathways.

This research was carried out under a contract with the Finnish Life Insurance Companies and was supported by the Medical Council of the Academy of Finland and the Sigrid Juselius Foundation. The authors thank Leena Kaipiainen and Irene TuomelaTörmänen for skilful technical and secretarial assistance.

Presented in abstract form in Gastroenterology 1983; 84: 1206.

\section{References}

1 Bennion LJ. Grundy SM. Risk factors for the development of cholelithiasis in man (Parts one and two). N Engl J Med 1978; 299: 1161-7, 1221-7.

2 Körner $\mathrm{G}$. Uber die familiäre Häufung der gallenblasen Krankheiten. Z für Menschliche Verarbungs und Konstitutionslehre 1937; 20: 528-82.

3 Jackson CE. Gay BC. Inheritance of gall-bladder disease. Surgery 1959: 46: 853-7.

4 Van der Linden W. Lindelof G. The familial occurrence of gallstone disease. Acta Genet Stat Med 1965: 15: 15964 .

5 Van der Linden W. Westlin N. The familial occurrence of gallstone discase. II Occurrence in husbands and wives. Acta Genet Stat Med 1966; 16: 377-82.

6 Van der Linden W. Simonsen N. The familial occurrence of gallstone disease. Incidence in parents of young patients. Hum Hered 1973; 23: 123-7.

7 Gilat T, Feldman C. Halpern Z. Dan M, Bar-Meir S. An increased familial frequency of gallstones. (iastroenterology 1983; 84: 242-6.

8 Admirand WH. Small DM. The physicochemical basis of cholesterol gallstone formation in man. $J$ Clin Invest 1968; 47: 1043-52.

9 Carcy MC. The enterohepatic circulation. In: Arias I. Popper H, Schachter D. Shafritz DA, eds. The liver: biology and pathobiology. New York: Raven Press, 1982: 429-65.

10 Kaprio J, Sarna S, Koskenvuo M, Rantasalo I. The Finnish Twin Registry: formation and compilation, 
questionnaire study, zygosity determination precedures, and research program. Twin research: biology and epidemiology. New York: Alan R Liss, 1978: 179-84.

11 Sarna S, Kaprio J, Sistonen P. Koskenvuo M. Diagnosis of twin zygosity by mailed questionnaire. Hum Hered 1978; 28: 241-54.

12 Sistonen P. Ehnholm C. On the heritability of serum high density lipoprotein in twins. Am J Hum Genet 1980; 32: 1-7.

13 Cederlöf R, Friberg L, Johnsson E, Kaij L. Studies on similarity diagnosis in twins with the aid of mailed questionnaires. Acta Genet Statist Med 1961; 11: 33862.

14 Nichols PC, Bilbro WC. The diagnosis of twin zygosity. Acta Genet Statist Med 1966; 16: 265-75.

15 Burke BS. The dietary history as a tool in research. J Am Diet Assoc 1947; 23: 1041-6.

16 Ahlström A, Räsänen L, Kuvaja K. A method of data processing for food consumption surveys. Ann Acad Sci Fenn 1972: 194: 1-8.

17 White EC. McNamara DJ, Ahrens EH. Validation of a dietary record system for the estimation of daily cholesterol intake in individual outpatients. Am J Clin Nutr 1981; 34: 199-203.

18 Färkkilä MA. Tilvis RS. Miettinen TA. Cholesterol absorption regulates cholesterol metabolism and plasma lipoprotein levels in patients with gut exclusions. Gastroenterology 1988; 94: 582-9.

19 Huang TC. Chen CP. Wefler V, Raftery A. A stable reagent for the Liebermann-Burchart reaction. Application to rapid serum cholesterol determination. Anal Chem 1961: 33: 1405-7.

20 Kessler G, Lederer H. Fluorometric measurement of triglycerides. In: Skeggs LT, ed. Automation in analytical chemistry. Technicon Symposium, 1965. New York: Mediad Inc, 1966: 341-4.

21 Grundy SM, Ahrens EH Jr. Miettinen TA. Quantitative isolation and gas-liquid chromatographic analysis of total fecal bile acids. J Lipid Res 1965; 6: 397-410.

22 Bartlett GR. Phosphorus assay in column chromatography. J Biol Chem 1959; 234: 466-8.

23 Fiske $\mathrm{CH}$, Subbarow $\mathrm{Y}$. The colorimetric determination of phosphorus. J Biol (hem 1925; 66: 375-400.

24 Miettinen TA. Serum squalene and methyl sterols as indicators of cholesterol synthesis in vivo. Life Sci 1969: 8: 713-21.

25 Jensen AR. Estimation of the limits of heritability of traits by comparison of monozygotic and dizygotic twins. PNAS USA 1967; 58: 149-56.

26 Christian JC. Feinleb M, Hulley SB, et al. Genetics of plasma cholesterol and triglycerides: a study of adult male twins. Acta Genet Med Gemellol /Romal 1976; 25: $145-9$.

27 Miettinen TA. Detection of changes in human cholesterol metabolism. Ann Clin Res 1970; 2: 300-20.

28 Miettinen TA. Effects of bile acid feeding and depletion on plasma and biliary squalene, methyl sterols and lathosterol. In: Paumgartner G, Stichl A. Gerok W. eds. Bile acids and lipids. Lancaster: MTP Press, 1981: 25.5-67.

29 Miettinen TA. Cholesterol precursors and their diurnal rhythm in lipoproteins of patients with jejuno-ilcal bypass and ilcal dysfunction. Metabolism 1985; 34: 425-30.

30) Björkhem I, Miettinen T, Reihner E, Angelin B, Ewerth S, Einarsson K. Correlation between serum levels of some cholesterol precursors and activity of HMG CoA reductase in human liver. $J$ Lipid Res 1987; 28: $1137-43$.

31 Miettinen TA. Diurnal variation of cholesterol precursors squalene and methyl sterols in human plasma lipoproteins. J Lipid Res 1982; 23: 466-73.

32 Miettinen TA, Kesäniemi YA, Järvinen H, Hästbacka J. Cholesterol precursor sterols, plant sterols and cholestanol in human bile and gallstones. Gastroenterology 1986; 90: 858-64.

33 Vlahcevic ZR, Bell CC Jr, Buhac I, Farrar JT, Swell L. Diminshed bile acid pool size in patients with gallstones. Gastroenterology 1970; 59: 165-73.

34 Bell CC Jr, Vlahcevic ZR, Prazich J, Swell L. Evidence that a diminished bile acid pool size precedes the formation of cholesterol gallstones in man. Surg Gynecol Obstet 1973; 136: 961-5.

35 Grundy SM, Metzger AL, Adler RD. Mechanisms of lithogenetic bile formation in American Indian women with cholesterol gallstones. J Clin Invest 1972: 51: 302643.

36 Grundy SM, Duane WC. Adler RD. Aron JM. Metzger AL. Biliary lipid outputs in young women with cholesterol gallstones. Metabolism 1974; 23: 67-73.

37 Trotman BW, Soloway RD. Pigment vs cholesterol cholelithiasis: clinical and epidemiological aspects. Dig Dis 1975; 20: 735-40.

38 Kesäniemi YA, Miettinen TA, Järvinen H, Hästbacka $\mathrm{J}$, Silvennoinen E. Noncholesterol sterols in gallstone and bile. J Hepatol 1985; S179-S371 (suppl 2): 264.

39 Danzinger RG, Gordon H. Schocnfield LJ, Thistle JL. Lithogenic bile in siblings of young women with cholclithiasis. Mayo Clin Proc 1972; 47: 762-6.

40) Holan KR, Holzbach RT, Herman RE, et al. Nucleation time: a key factor in the pathogenesis of cholesterol gallstone discase. Gastroenterology 1979; 77: 611-7.

41 Sedaghat A. Grundy SM. Cholesterol crystals and the formation of cholesterol gallstones. $N$ Engl J Med 1980; 302: $1274-7$.

42 Gollish SH. Burnstein MJ. Ilson RG. et al. Nucleation of cholesterol monohydrate crystals from hepatic and gallbladder bile of patients with cholesterol gallstone. Gut 1983; 24: 836-44.

43 Kesänicmi YA. Grundy SM. Clofibratc, caloric restriction, supersaturation of bile, and cholesterol crystals. Scand J Gastroenterol 1983; 18: 897-9(2).

44 Hofmann AF. Grundy SM. Lachin JM. et al. Pretreatment biliary lipid composition in white patients with radiolucent gallstones in the National Cooperative Gallstone Study. Gastroenterology 1982; 83: 738-52. 